\title{
Study of the effect of the shape of the miniplate on the stability of mandibular symphyseal fracture using finite element analysis
}

\section{Original Article}

\author{
Altaib Abdalrazik Mohammed \\ Department of Oral and Maxillofacial Surgery, Faculty of Oral \& Dental Medicine, \\ South Valley University, Qena, Egypt
}

\begin{abstract}
Introduction: Finite element analysis is a new technology used for mechanical designing, and showing the behavior of the body when subjected to different loads as regards the resulted stresses and displacement.

Aim: The aim of this research was to detect the effect of the miniplate shape on stability of the mandibular symphyseal fracture. Patients/Methods: Through this study two configurations of the miniplates were compared. The two miniplates are equal in length, width, thickness and of the same material, only they are different in shapes, one plate was straight and the other was L shaped, they are investigated using three dimensional finite element software.

Results: There was no significant difference between straight and L shaped miniplate, however the L shaped miniplate was slightly superior to straight miniplate as regard plate stability.

Conclusion: There is no significant difference between the different systems. The shape of miniplate may have a role in stability of mandibular fracture stability, the same plate shows different behavior when fixed at different positions double plate shows more stability than single one ,of the same shape finite element technology is helpful means for designing of different fixation systems.
\end{abstract}

Key Words: Biomechanics, finite analysis, plate shape, symphyseal fracture

Received:18 April 2018, Accepted: 29 July 2018

Corresponding Author: Altaib Abdalrazik Mohammed, Department of Oral and Maxillofacial Surgery, South Valley University, Qena, Egypt, Tel.: 01223046874, E-mail: altaib.mohamed@dent.svu.edu.eg, Kena20052006@yahoo.com

ISSN: 2090-097X, May 2018, Vol. 9, No. 2

\section{INTRODUCTION}

Mandibular symphysis is the most prominent part of the mandible and more liabe to fracture it represents $35 \%$ of mandibular fracture ${ }^{[1]}$ due to surrounding conditions as muscle pull and bite force mandibular symphysis show complex biomechanics, the most prominent displacement was due to negative bending where there is compression at the superior border and tension on the lower border , also the most prominent torque through the mandible was discovered at the symphyseal region so any fixation system used to manage symphyseal fracture must resist the mentioned ,movements, according to the study of Tams et al. ${ }^{[2]}$

It was stated in the literature that fracture displacement should not exceed $150 \mu \mathrm{m}$ for proper healing ${ }^{[3]}$. There are multiple factors affecting the stability of the fixation system as regards the dimensions, numbers and position of the fixation systems, however the study of the effect of the shape of plate on fracture stability was little through the literature. ${ }^{[4]}$

Also, there continuing biomechanical trials to simulate the biomechanics of the mandibular symphysis, recently three dimensional finite element analysis can be used to study the complex mandibular biomechainics. ${ }^{[5]}$

So that, the aim of this study was to determine the effect of the shape of miniplate on stability of mandibular symphyseal fracture using finite element analysis.

\section{MATERIALS AND METHODS}

The region of symphyseal fracture was simulated simply by sketching the fracture through an acrylic block which is 15 thickness and 40 in height as the same dimensions of the symphysis according to the study of Alkhateeb et $a l^{[6]}$.

The titanium miniplate of straight shape and L was simulated having the same length $(28 \mathrm{~mm})$ and width $(4 \mathrm{~mm})$ and thickness $1 \mathrm{~mm})$ also with the same diameter and number of holes ( 6 holes) the plate fixed to the acrylic bar using miniplate screw $2 \mathrm{~mm}$ in diameter and $11 \mathrm{~mm}$ in length, each type of plate was simulated to fixate the fracture at different pattern as following:

1- single straight plate at the superior border( SSS)

2- single straight plate at the middle(SSM) 
3- single straight plate at the lower border(SSL)

4- single L shaped plate at the superior border(SLS)

5- single L shaped plat at the middle(SLM)

6--single L shaped plat at the lower border(SLL)

7- double straight plates one at the superior border and the other at the lower border(DS)

8- double L shaped plate one at the superior border and the other at the lower border(DL)

Each system was simulated in three dimensional finite element analysis software (Fusion 360 provided by AUTODISK) and the material properties was as shown in the Tables $(1,2)$ and these properties derived from the library of the used software.

Table 1: showing material properties of titanium

\begin{tabular}{ll}
\hline Density & $4.51 \mathrm{E}-06 \mathrm{~kg} / \mathrm{mm}^{\wedge} 3$ \\
\hline Young's Modulus & $102810 \mathrm{MPa}$ \\
Poisson's Ratio & .3 \\
Yield Strength & $275.6 \mathrm{MPa}$ \\
Ultimate Tensile Strength & $344.5 \mathrm{MPa}$
\end{tabular}

Table 2: material properties of acrylic block

\begin{tabular}{ll}
\hline Density & $1.188 \mathrm{E}-06 \mathrm{~kg} / \mathrm{mm}^{\wedge} 3$ \\
\hline Young's Modulus & $2740 \mathrm{MPa}$ \\
Poisson's Ratio & .3 \\
Yield Strength & $48.9 \mathrm{MPa}$ \\
Ultimate Tensile Strength & $79.8 \mathrm{MPa}$ \\
\hline
\end{tabular}

\section{Boundary conditions}

Each system was tested for negative bending by application of load 100 newton at the fracture site at the superior border while both distal surfaces on both right and left site were fixed for all directions (X, Y,Z) Also each system was tested for torque moment by fixation of the left distal surface and application of torque force $100 \mathrm{~N}$ on the right distal surface, the effect of friction of plates with the underlying substrate(acrylic bars), and also between the surfaces of the substrates at the fracture site was abolished by selection separation type of bond, so that the applied bite force transmitted from the acrylic bar to the fixed screw then to the plate then from the plate to the other acrylic bar on case of torque.
All the materials used throughout this study was isotropic and linear according to the study of Wang ${ }^{[7]}$.

High convergence was done for all the results, as regards the von Mises stresses and displacement according to the study of Ayal and Ekmen ${ }^{[8]}$. The numbers of nodes and elements for the used models for the used models are presented in Table 3.

Table 3: number of nodes and elements of the used models

\begin{tabular}{lll}
\hline The model & Number of nodes & $\begin{array}{l}\text { Number of } \\
\text { elements }\end{array}$ \\
\hline $\begin{array}{l}\text { Model of the } \\
\text { single straight } \\
\text { miniplate }\end{array}$ & 27970 & 17352 \\
$\begin{array}{l}\text { Model for the L } \\
\text { shape miniplate }\end{array}$ & 25149 & 15459 \\
$\begin{array}{l}\text { Model for the } \\
\text { double straight } \\
\text { miniplate }\end{array}$ & 65336 & 42223 \\
$\begin{array}{l}\text { Model for the } \\
\text { double L shape } \\
\text { miniplate }\end{array}$ & 62031 & 39640 \\
\hline
\end{tabular}

\section{RESULTS}

\section{As regards bending moments (Figures1-6)}

Finite element analysis through this study depended on the displacement and stresses generated through the miniplates, on application of vertical bending load displacement occur on $\mathrm{x}, \mathrm{y}, \mathrm{z}$ directions the mean displacements through these directions were calculated and this is summerized through Table 4 and Figures 9-16 no model shows displacement more than 150 micrones , both single straight and L shaped pate show the highest displacement at the lower boder however the displacement through the single $\mathrm{L}$ shaped plate was less than that single straight plate, double straight plate showed less displacement than both single straight and $\mathrm{L}$ shaped plate and this is obvious at the lower border plate.

While double L shape plate shows less displacement than double straight plate.

As regards the resulted von Mises stresses on bending measured in megapascal throught the miniplates, these stresses did not exceed the yield limit of titanium in all groups, the highest stress was noticed at the inferior border 
plates but single L shaped plate is less stressed than the single straight plate while lower border plate in double straight system showed less stress than single straight and L shaped single plate, as regards the double L shaped plate system showed the least stress of all systems either at the superior border plate or inferior border plates.

Fig. 1: Displacement on bending through single straight plate
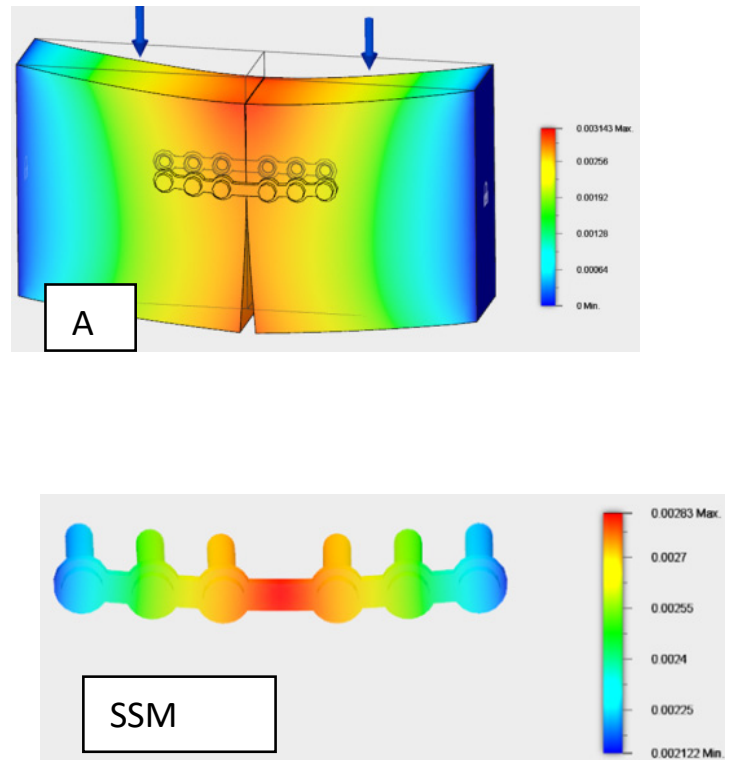

FIGURE showing displacement on bending through:

A-single straight plate at the superior border and surrounding region SSS- -single straight plate atr the superior border

SSM- single straight plate at the middle

SSL0-single straight plate at the lower border

Fig. 2: Displacement on bending through single L plate
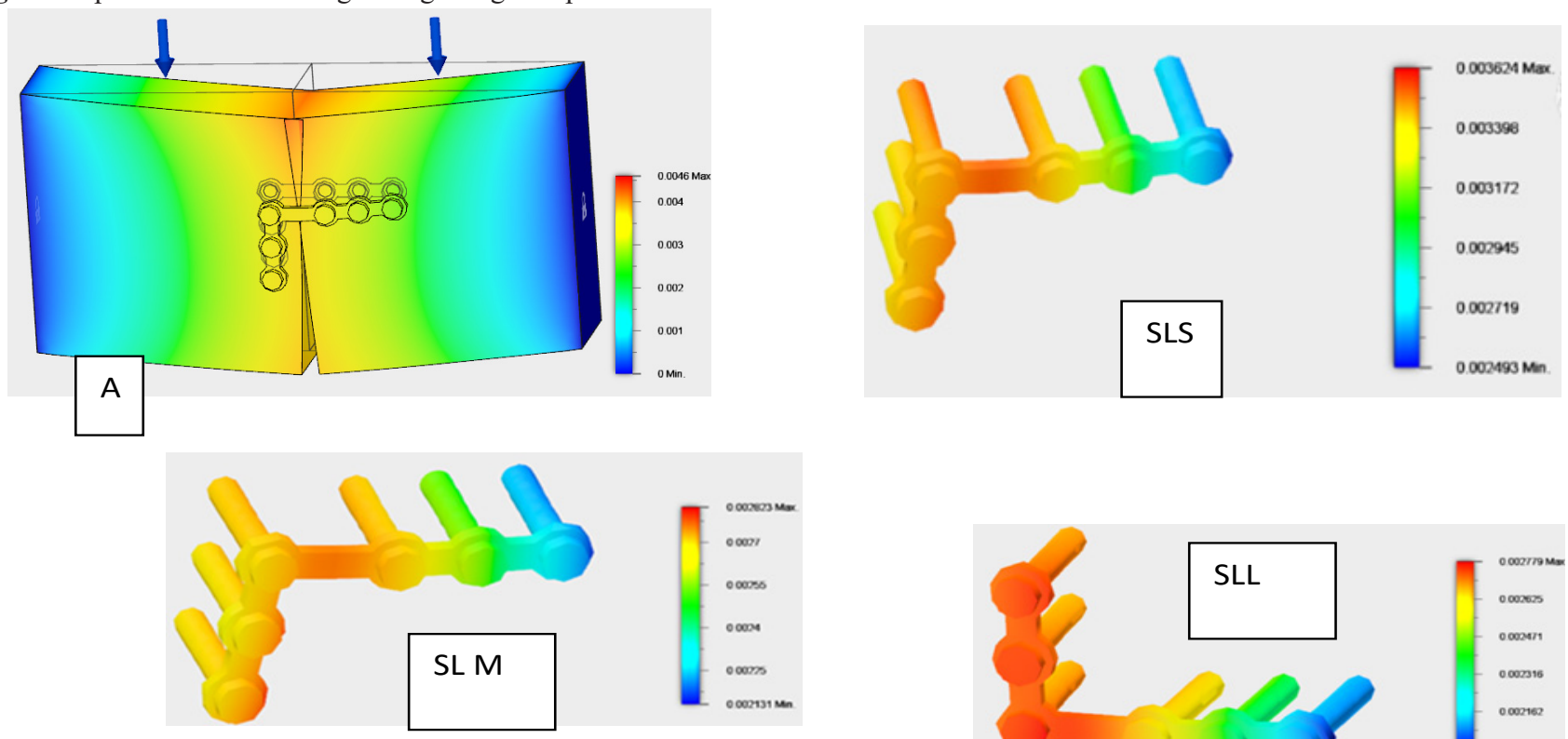

Figure showing displacement on bending through:

A-single 1 shaped plate on the superior border and surrounding region SSS- single L shaped plate

SLM- single 1 shaped plate on the middle

SSL - SINGLE L shaped plate at the lower border
It is noted that as the bending stress increased gradually the displacement also increased in linear relation ship as shown on linear graph 1 which demonistrates that single L shaped plate is more stable than single straight shaped plate, also double $\mathrm{L}$ shaped plate is more stable than double straight plates.
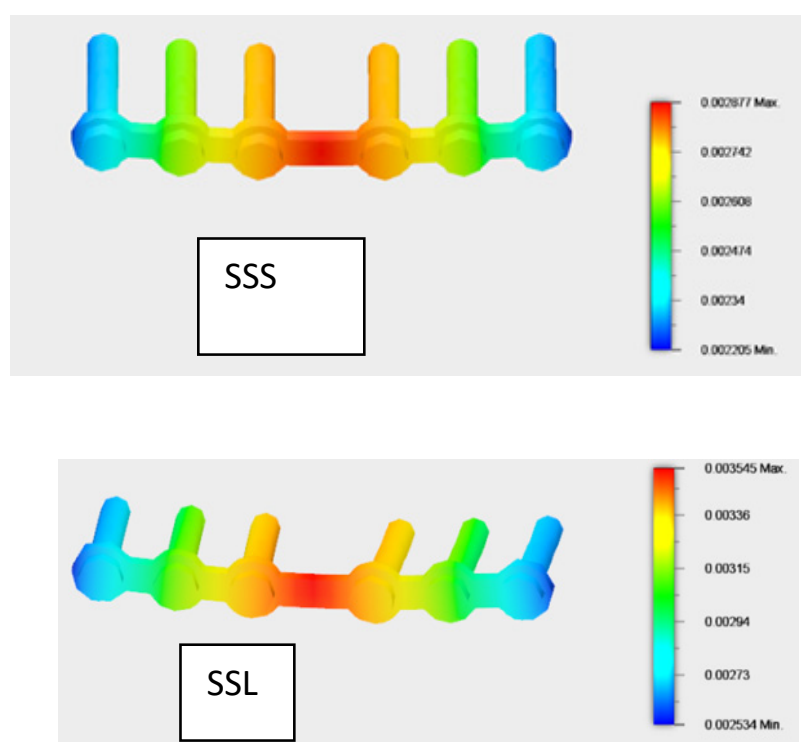
Fig. 3: Displacement through double straight and double L shape plate
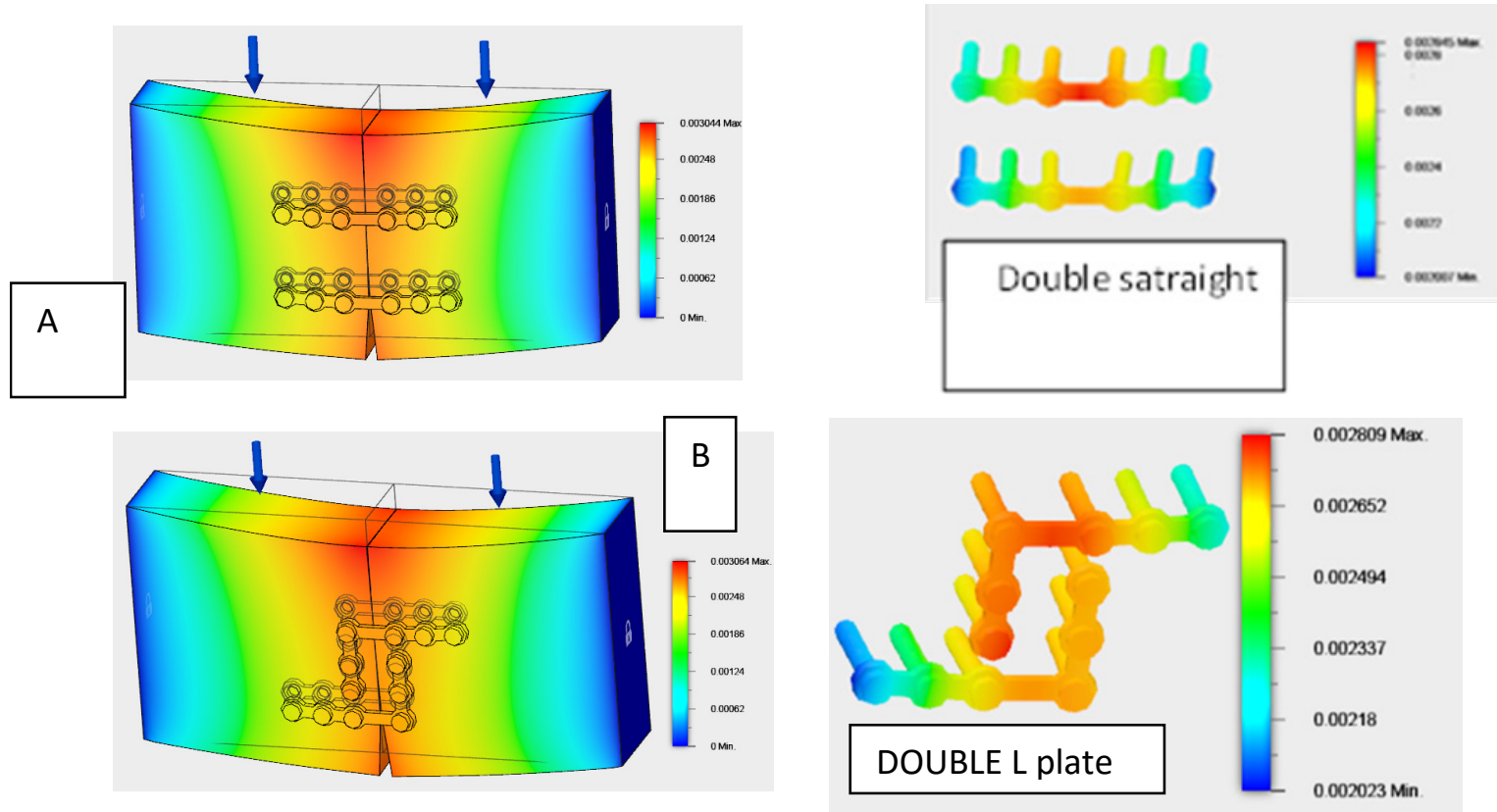

Figure showing displacement on bending through :

Double straight plate and surrounding region

Double straight plate

Double L shaped plate

Fig. 4: Stress on bending through single straight plate
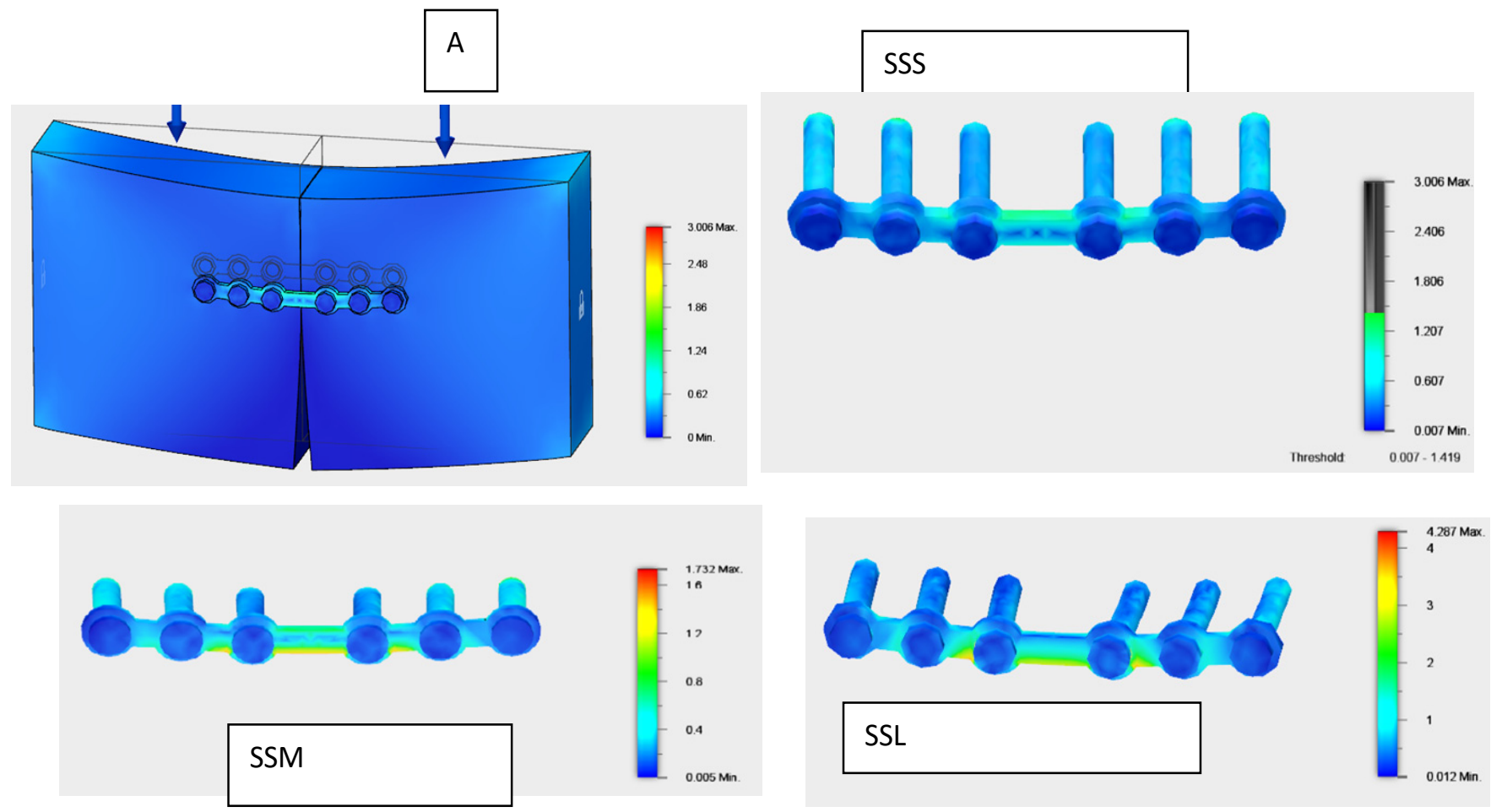

A- Stress distribution through the superior border single straight plate and surrounding region SSS- Stress distribution through the superior border single straight plate SSM- Stress distribution through the middle single straight plate 
Fig. 5: Stress on bending through single L shaped plate
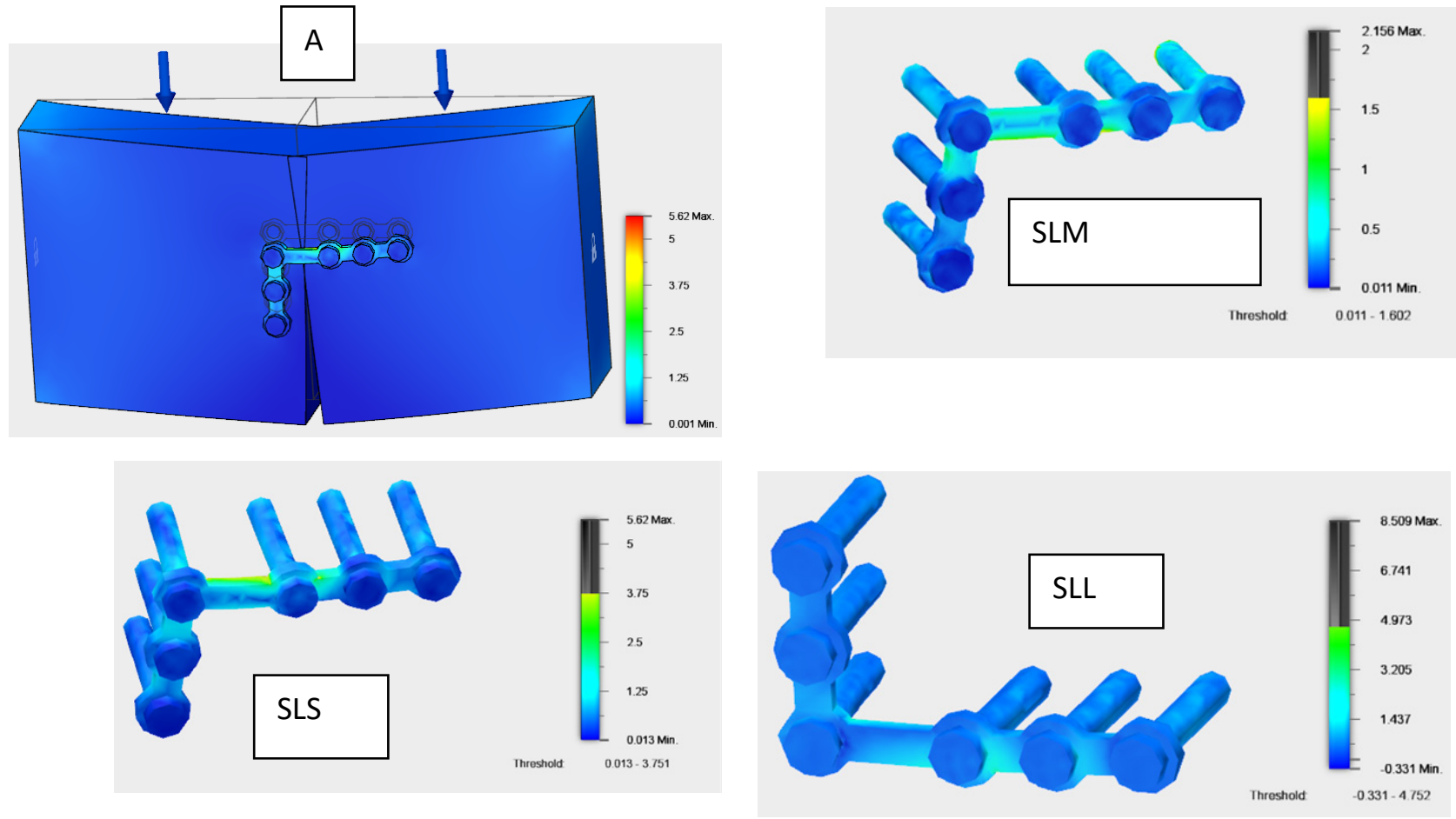

Stress distribution through

A-single L shaped plate at the superior border and surrounding region

SLS-single L shaped superior border plate

SLM- single L shaped plate at $r=$ the middle

SLL- single L shaped plate at the lower border

Fig. 6: Stress on bending through double L shaped plate and double straight plate
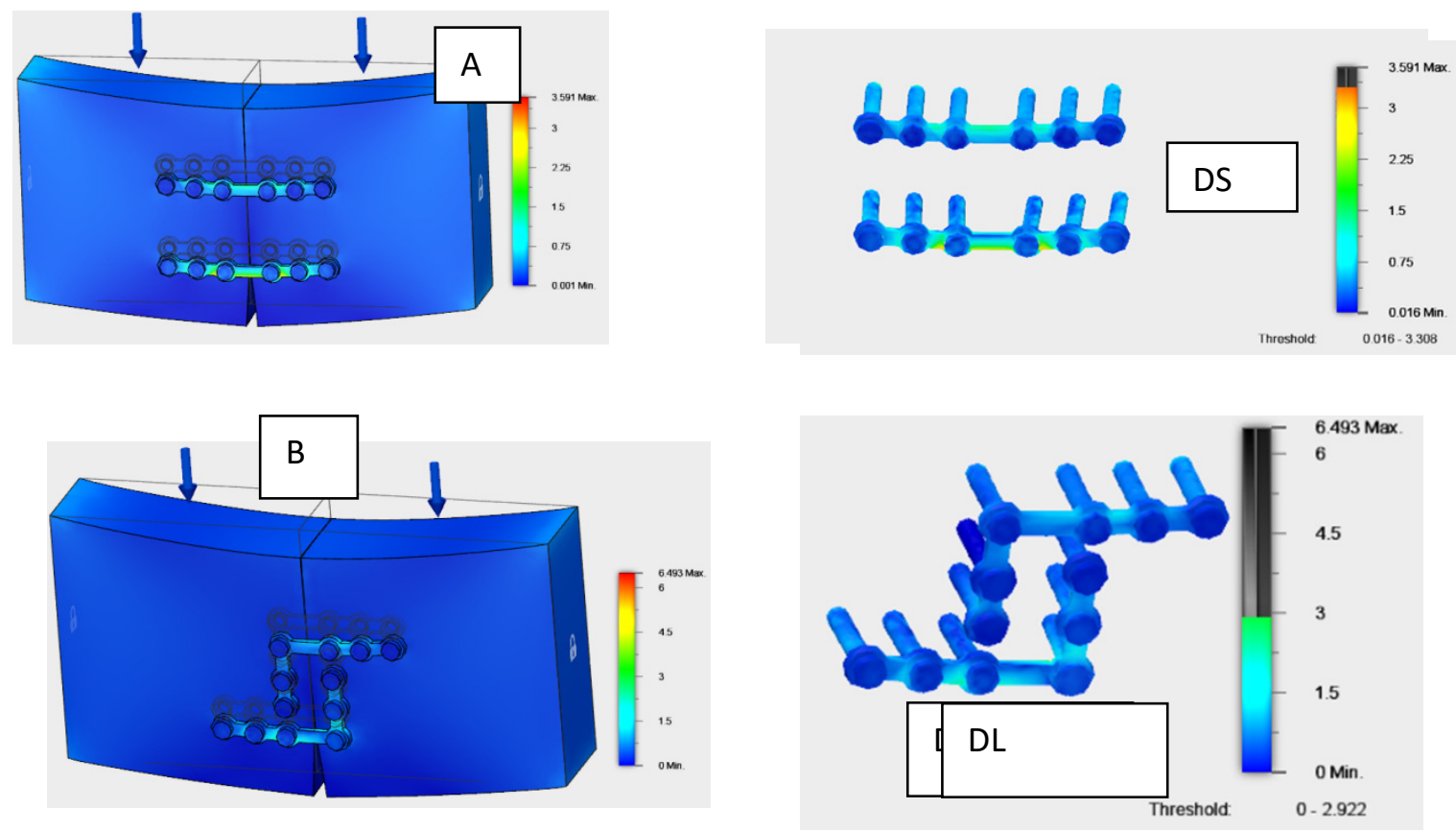

Stress distribution through

A-Double straight plates and surrounding region

B- Double L plate and surrounding region

DS-Double straight plate

DL-Double shaped plate 
Table 4: showing stress in mega pascal and displacement in $\mathrm{mm}$ through different categories on bending

\begin{tabular}{|c|c|c|c|c|c|c|c|c|c|c|c|c|}
\hline Variable & SSS & $\mathrm{SSm}$ & SS1 & SLS & $\mathrm{S} 1 \mathrm{~m}$ & SLl & $\begin{array}{c}\text { Superior plate } \\
\text { of DS }\end{array}$ & $\begin{array}{l}\text { Inferior } \\
\text { plate } \\
\text { of DS }\end{array}$ & DS total & $\begin{array}{c}\text { Superior } \\
\text { plate } \\
\text { of DL }\end{array}$ & $\begin{array}{l}\text { inferior } \\
\text { plate of } \\
\text { DL }\end{array}$ & DL total \\
\hline Vonmeses & 1.419 & 1.732 & 4.287 & 3.751 & 1.602 & 3.688 & 1.379 & 3.413 & 3.309 & 1.274 & 3.251 & 2.922 \\
\hline Displacement & 0.002877 & 0.00283 & 0.003545 & 0.003624 & 0.002823 & 0.002779 & 0.002845 & 0.002758 & 0.002845 & 0.002809 & 0.002743 & 0.002809 \\
\hline
\end{tabular}

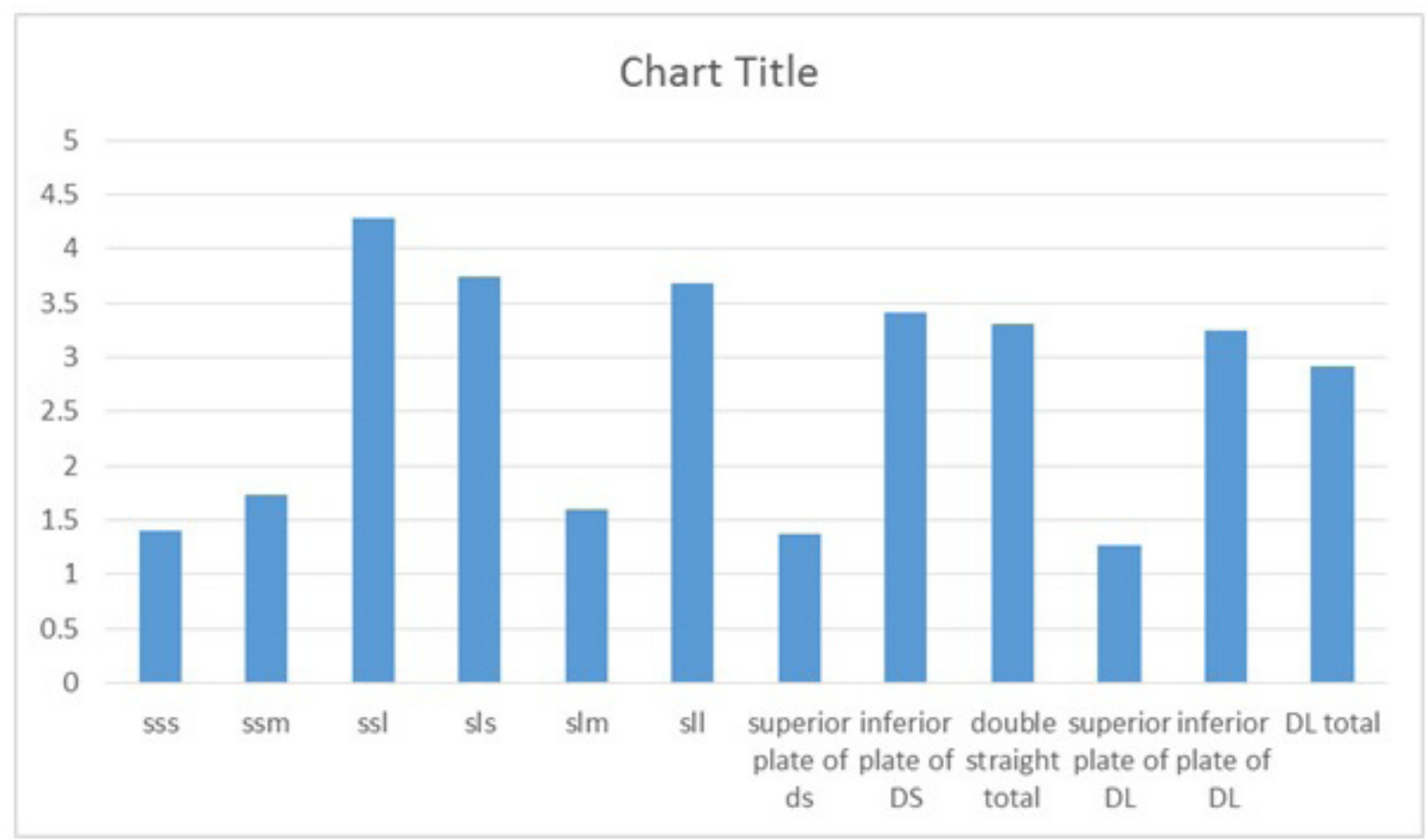

CHART BAR 1 showing stress distribution through different fixation systems

SSS single straight plate at superior border

SSm single straight plate at the middle

SSl single straight plate at the lower border

SL s single L shape plate at the superior border

SLm single 1 shape plate at the middle

SL 1 single L shape plate at the lower border

DS double straight

DL double L shape plate 


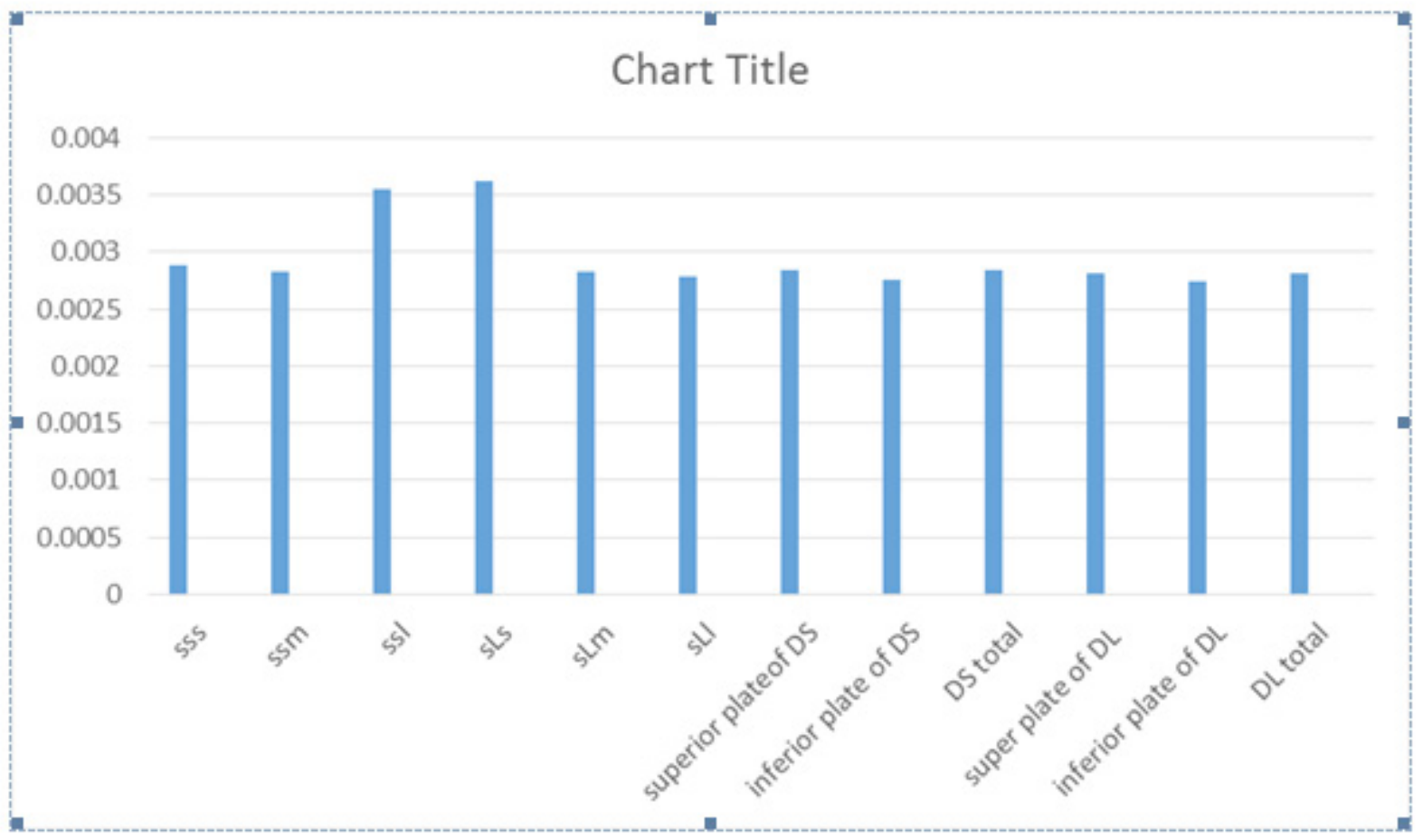

Chart bar 2 showing displacement mm of different systems

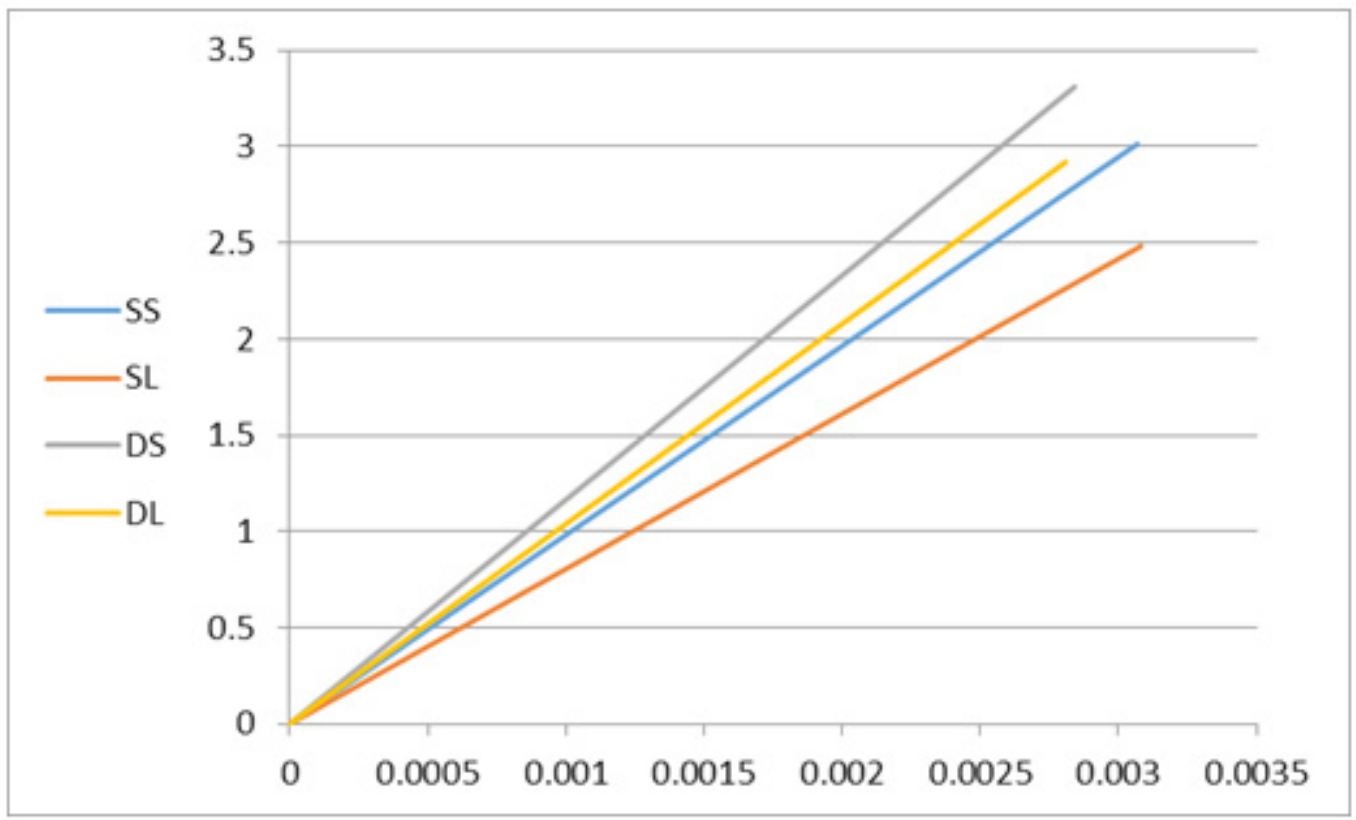

Linear graph 1 showing relation between displacement on horizontal axis and stress on vertical axis through different groups on bending SS-single straight plate SL - single L shaped plate DL - double plate

DL double L shaped plate 


\section{As regard torque moment}

Both torque stress and displacements shown on Figures (7-12) and Table 2 and Chart bar 3 and 4.

As regard single straight plate is highly stressed on inferior border than on superior border and least torque stress resulted on the middle position, the 1 shaped plate shows less torque stress than straight single plate in all positions, in the same time double straight plate system is less torque stress than single straight plate and 1 shaped single plates, while double 1 shaped plate show the least stress of all systems.

As regards displacement resulted due to torque the single L shaped plate showed less displacement than single straight plate, while double straight plate showed less displacement than single straight and single L shape plate, lastly the double L shape plate showed the least torque displacement and it is to be noted that as the stress increased the displacement also increased in linear relationship, the highest stress is met by highest displacement and the vice versa.

It is to be noted that there is linear relationship between stress and displacement on torque as shown in linear graph 2 which demonistrates that single L shaped plate is more table than single straight shaped plate, also double L shaped plate is more stable than double straight plates.

Fig. 7a: showed stress distribution through single straight plate
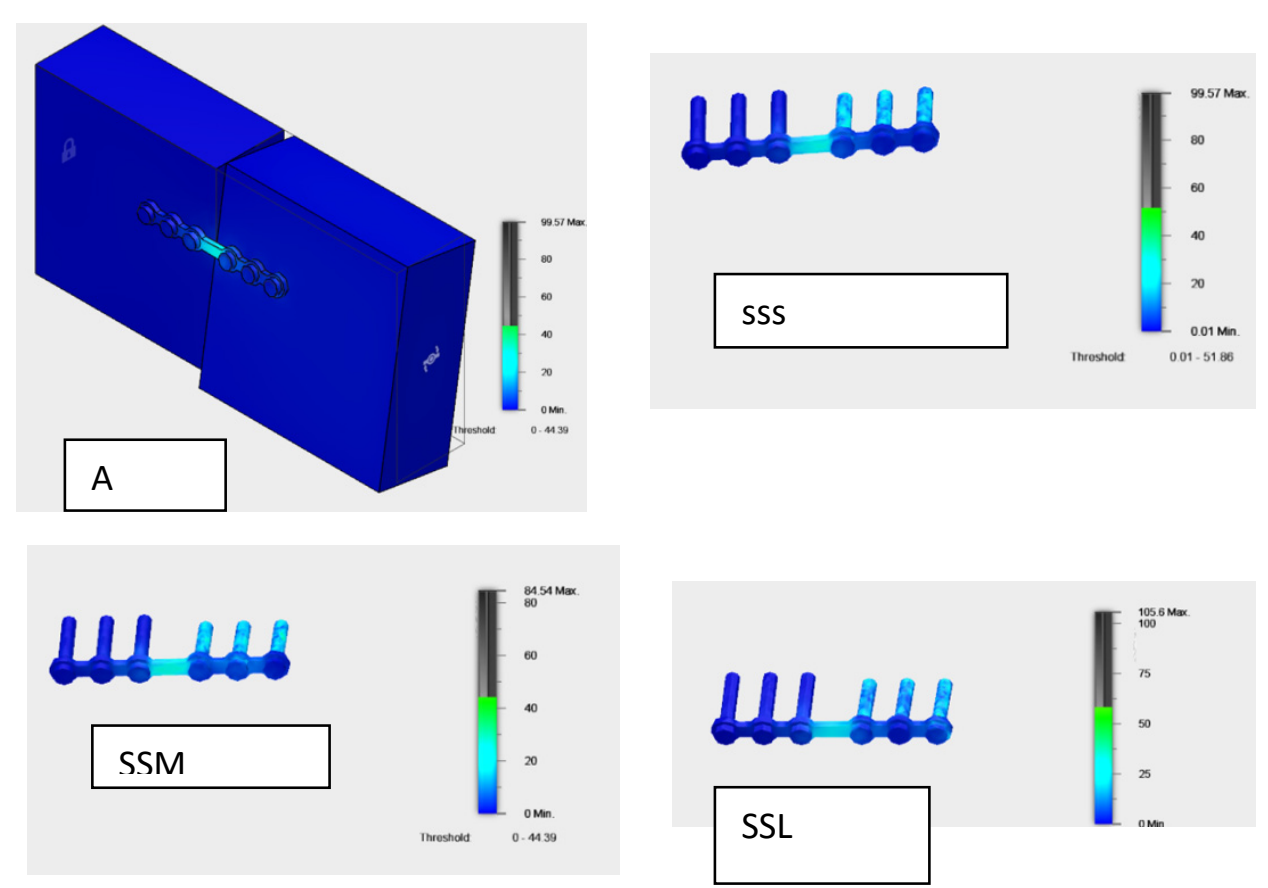

Stress distribution on torque through

A-stress distribution through single straight plate and surrounding region

SSS- single straight plate at the superior border

SSS- single straight plate at the middle

SSL- single straight plate at the lower border 
Fig. 8: stress distribution through the single L plate
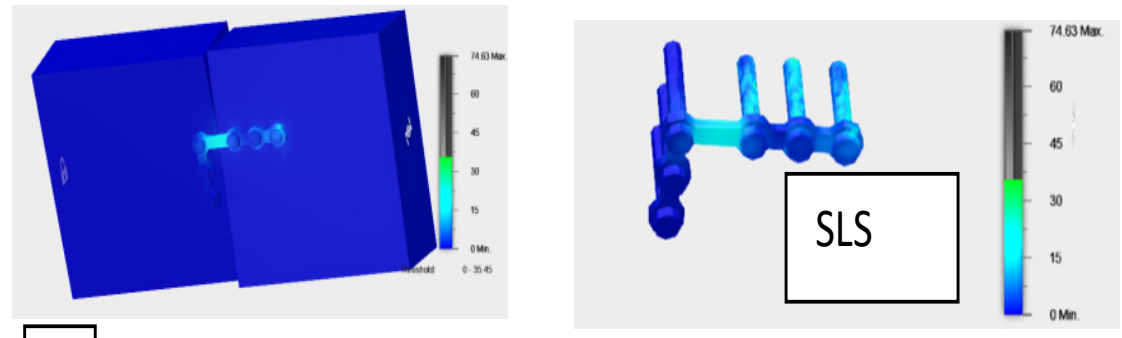

\section{A}
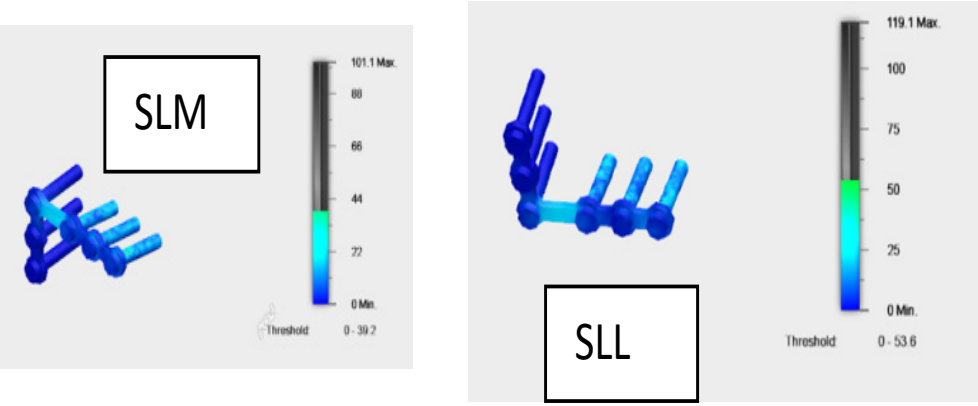

Figure showing stress distribution through $\mathrm{L}$ shaped plate

SLS - single L shaped plate at superior border

SLM- single 1 shaped plate at the middle

single 1 shaped plate at the middleSSL

Fig. 9 a: showed stress distribution through double straight and double L plate
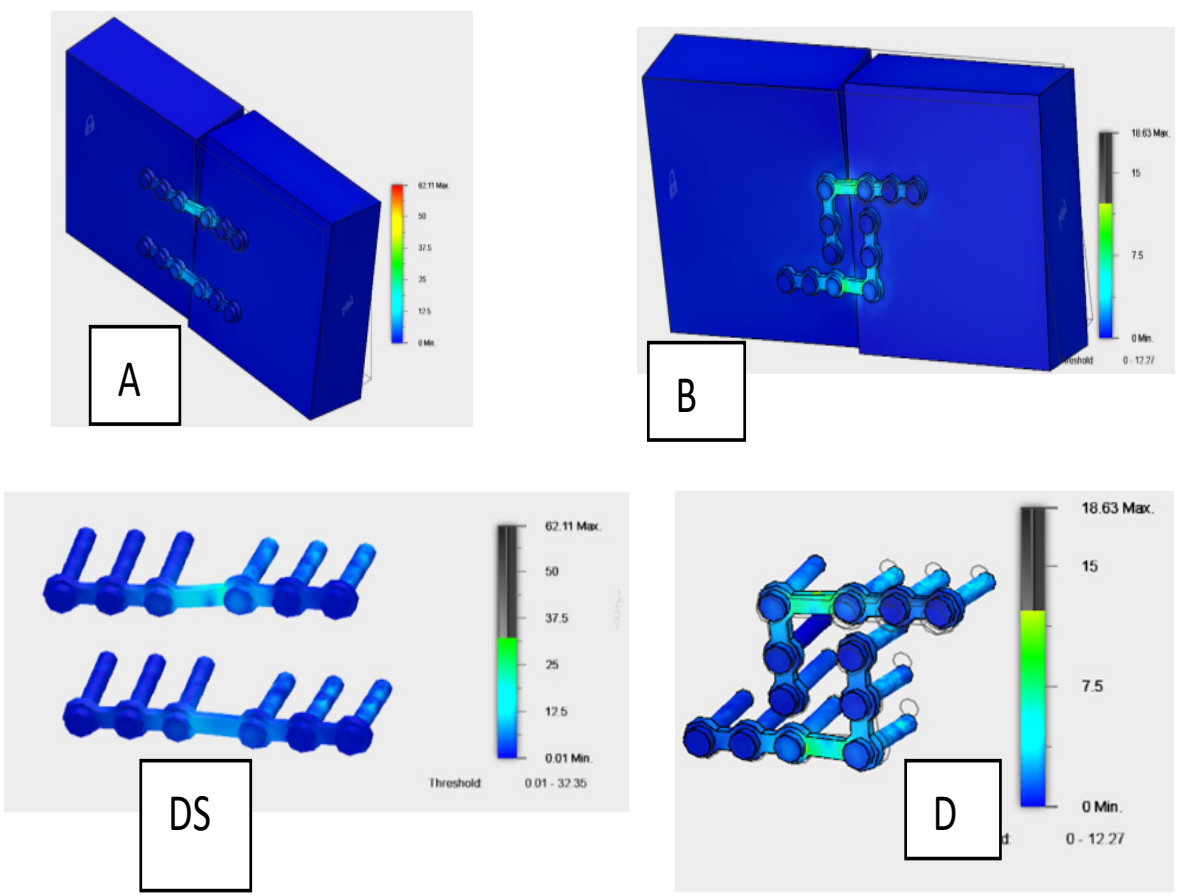

Figure showing stress distribution on torque through:

A-double straight plate and surrounding region

B- Double L shaped plate and surrounding region

DS- double straight plate

DL- double L shaped plate 
Fig. 10: displacement through single straight plate
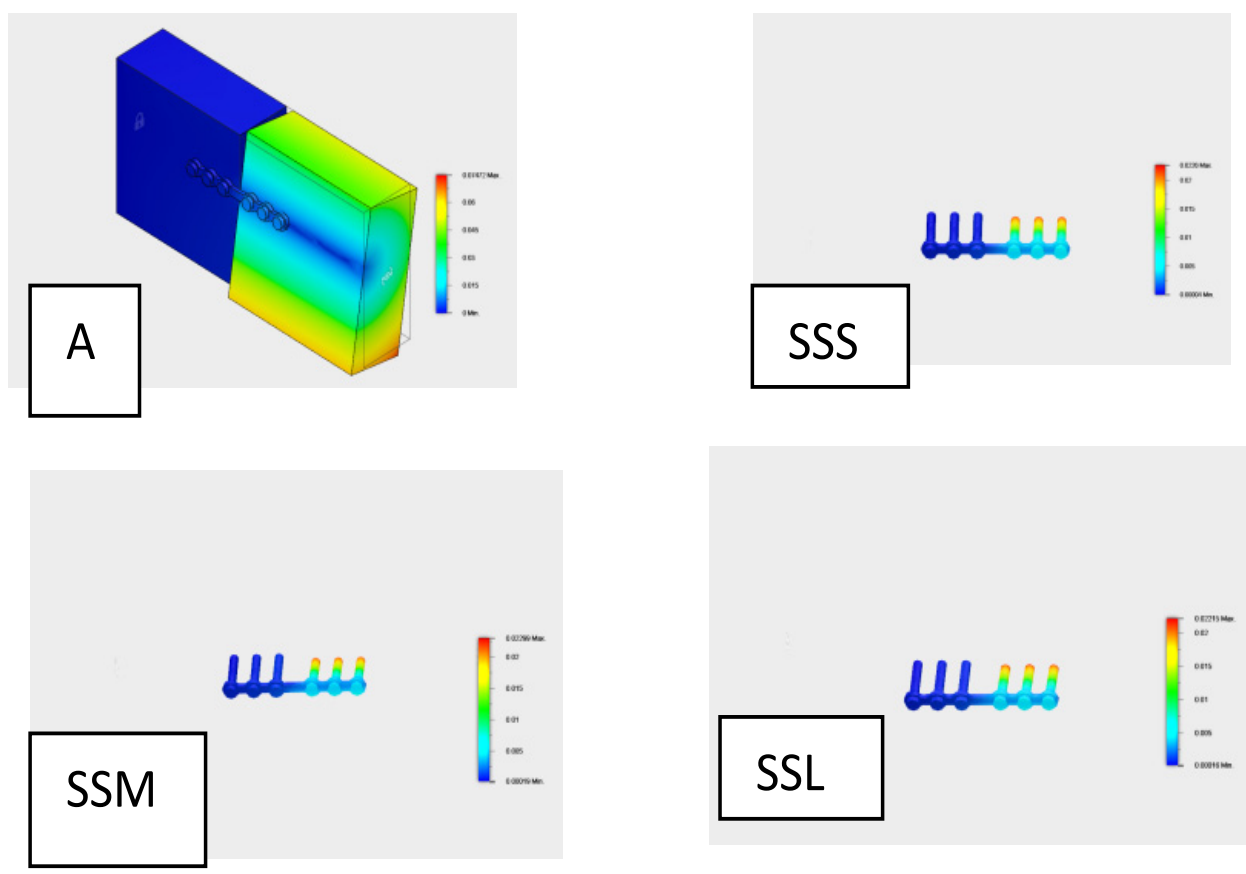

Figure showing displacement on torque through

A-single straight plate superior border and surrounding region

SSS-single straight plate at superior border

SSM-single straight plate at the middle

SSL-single straight plate at the lower border

Fig. 11: displacement through single L plate
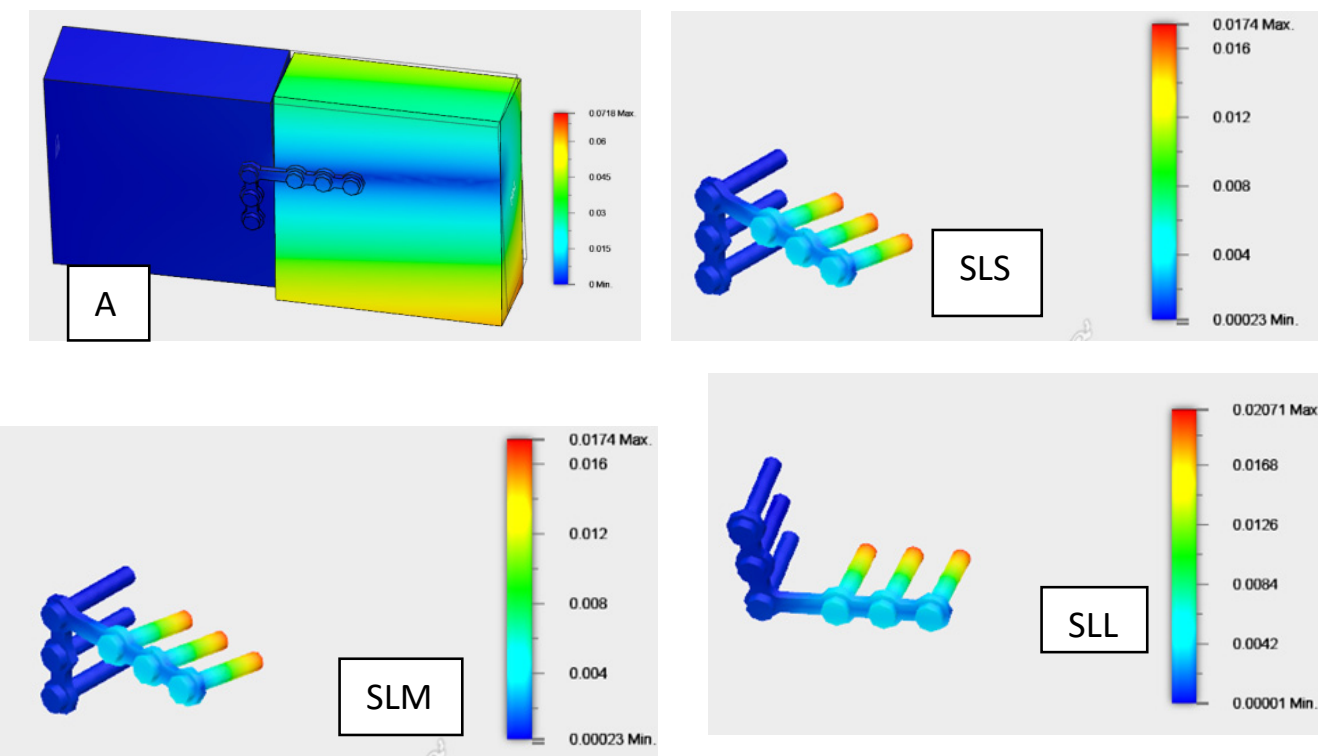

Figure showing displacement on torque through

A-single $\mathrm{L}$ shaped plate at the superior border and surrounding region SSS-single straight plate at the superior border

SSM-single straight at the middle

SSL- single straight plate at the lower border 
Fig.12: displacement through double straight and L shaped plate
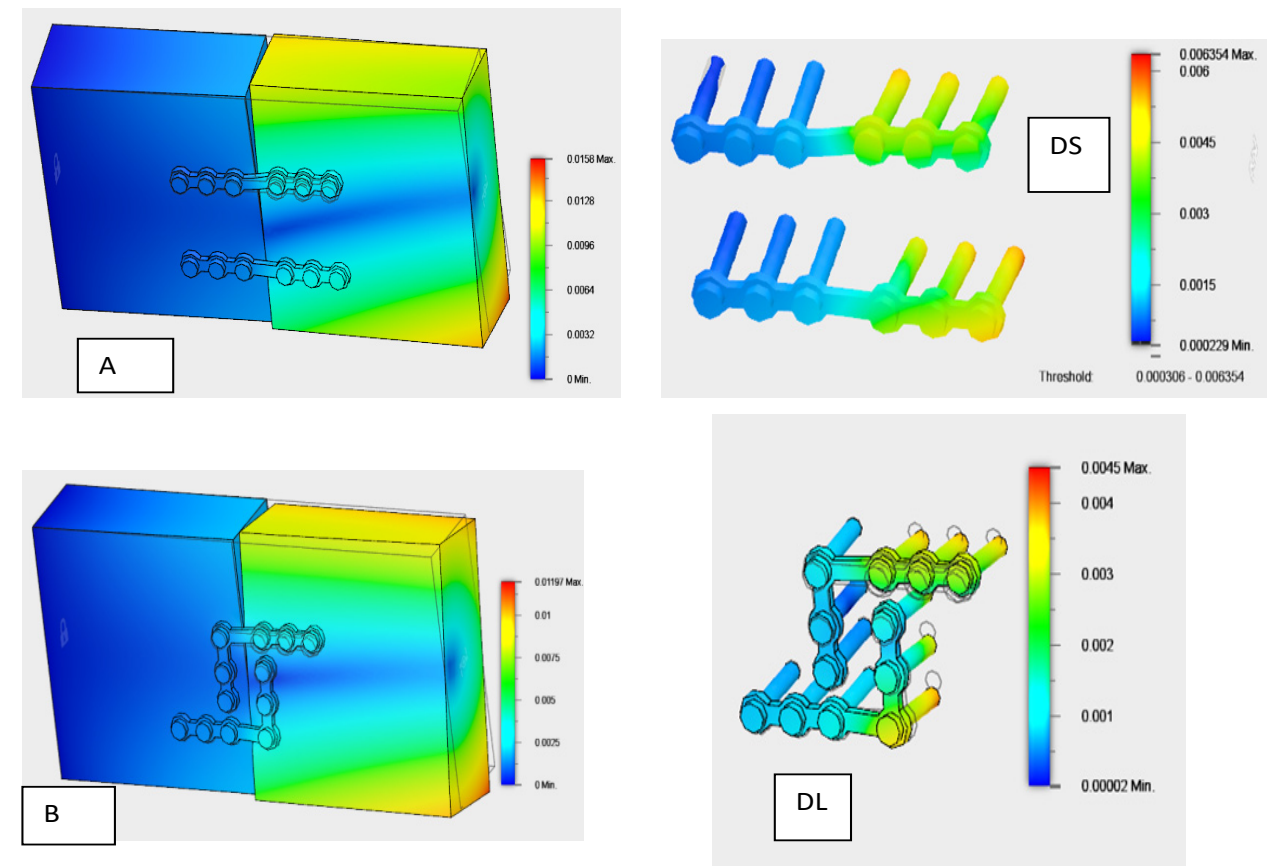

Figure showing displacement through:

A- Double straight plates and surrounding region

B- Double L shaped plate and surrounding region

DS-double straight plates

DL -double L shaped plate

Table 5: showing stress in mega pascal and displacement in $\mathrm{mm}$ through different categories on torque

\begin{tabular}{|c|c|c|c|c|c|c|c|c|c|c|c|c|}
\hline Variable & SSs & $\mathrm{SSm}$ & SS1 & SLs & SLm & SLl & $\begin{array}{c}\text { Superior plate } \\
\text { of DS }\end{array}$ & $\begin{array}{l}\text { Inferior } \\
\text { plate } \\
\text { of DS }\end{array}$ & DS total & $\begin{array}{c}\text { Superior } \\
\text { plate } \\
\text { of DL }\end{array}$ & $\begin{array}{c}\text { inferior } \\
\text { plate of } \\
\text { DL }\end{array}$ & $\begin{array}{l}\text { Double } \\
\text { L total }\end{array}$ \\
\hline Vonmeses & 51.86 & 44.39 & 58.5 & 35.45 & 39.2 & 53.6 & 32.36 & 10.95 & 37.35 & 25.81 & 10.02 & 26.555 \\
\hline Displacement & 0.0226 & 0.02299 & 0.02215 & 0.02065 & 0,0174 & .02071 & 0.005579 & 0.006354 & 0.006354 & 0.005955 & 0.004594 & 0.005955 \\
\hline
\end{tabular}




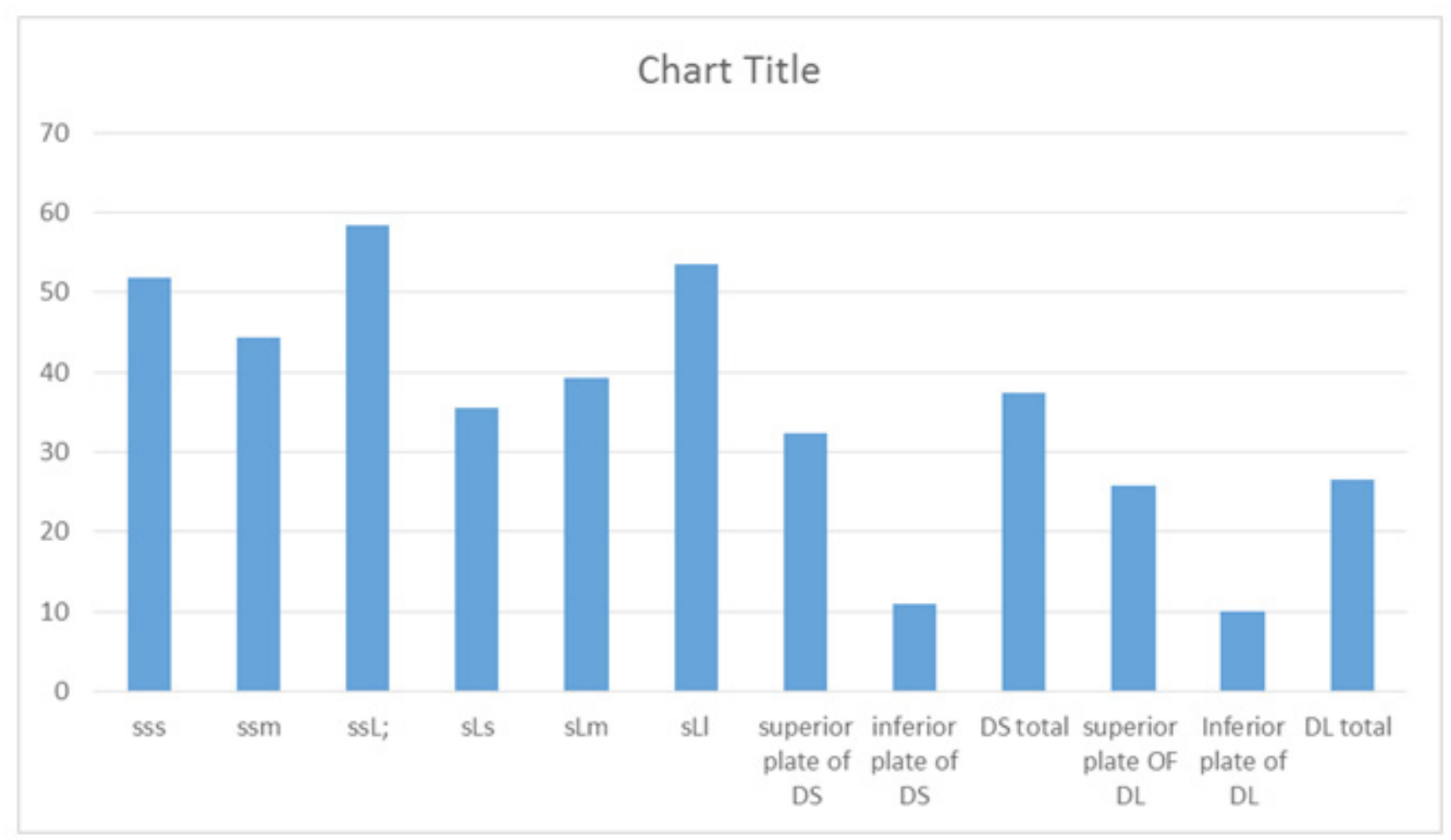

Chart bar 3 showing stress distribution through the different systems on torque

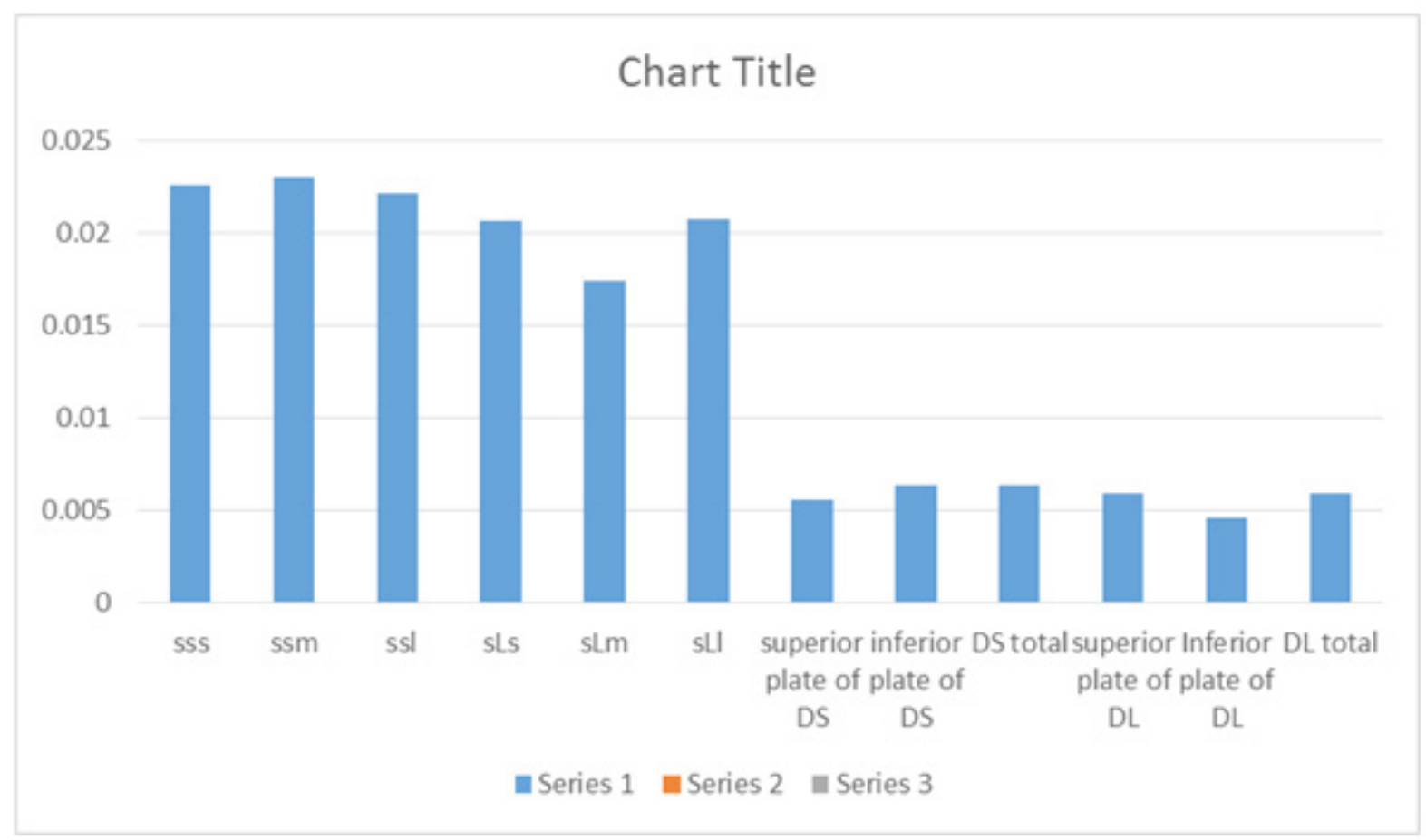

Chart bar 4 showing displacement through different system on torque 


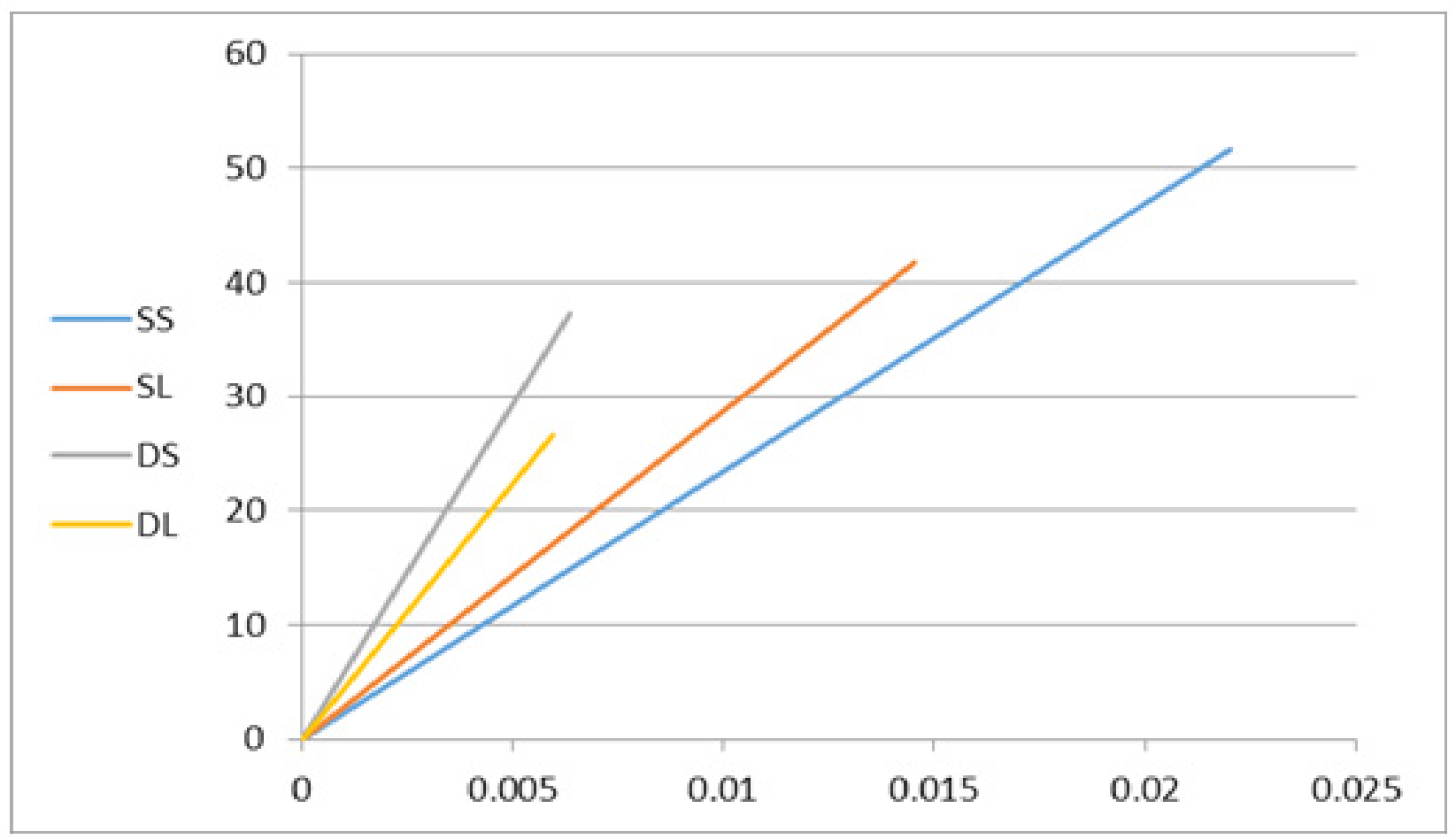

Linear graph 1 showing relation between displacement on horizontal axis and stress on vertical axis through different groups on torque SS-single straight plate $\mathrm{SL}$ - single L shaped plate DL - double plate DL double L shaped plate

\section{DISCUSSION}

Finite element analysis is a computational numerical new technology used to simulate any structure, which is divided into finite elements through a process called meshing, then the material properties of this structure are recorded by this method, then the structure subjected virtually to different forces and controlled by certain boundary conditions, the resulted stresses, strains and displacements are calculated through this methods ${ }^{[9]}$.

Finite element analysis used for multiple maxillofacial applications as trauma, orthognathic surgery, prosthodontics and orthodontic work. ${ }^{[10]}$

Multiple researches have studied the biomechanical behavior of the mandible that is fractured at the angle and condylar process after reduction and fixation with miniplate using finite element analysis however the symphyseal fracture has not explored sufficiently. ${ }^{[1,12]}$

Through this study, the fractured segment of the mandible was represented with two separated blocks having the same dimensions of the mandibular symphysis as regards the height, the width and thickness according to the study of Alkhateeb et al. ${ }^{[6]}$.
All the materials used through this study were considered homogenous, isotropic and linearly elastic in contrary to the facts that the mandibular bone is anisotropic and viscoelastic, these acts done to facilitate the study, and multiple studies used these considerations for the same purposes $^{[7,13]}$.

According to Tam study ${ }^{[2]}$, on application of bite forces on the occlusal plane, the symphyseal region reveals negative bending moment where there is compression at the upper border and tension at the lower border, while on molar loading there is torque moment.

While the normal bite force ranges from 600 to 800 newton according to the study of Hsu et al. ${ }^{[14]}$, the selected bite force for this study was 100 newton this is because of reduction of the bite force on traumatized mandible due to pain, edema and mutilation of the traumatized tissue according to the study of Kshirsagar et al. ${ }^{[15]}$ were the bite force may be reduced to $3-27 \mathrm{~kg}$ or $(29-264 \mathrm{~N})$ and application of $100 \mathrm{~N}$ through biomechanical study also stated through the study of Haug et al. ${ }^{[16]}$

Through this study, on application of bite force at occlusal plane on both side of the fracture, the model showed negative bending moment and this is the same 
that occurs at symphysis region according to the study of Tam et al. ${ }^{[2]}$

As regards single plates either straight or L shaped plate, it is obvious that the plate position affect stress distribution, the inferior border positioned plate is highly stressed than middle and superior border positioned plate, this is because the high tension resulted at the lower border due to negative bending, the $\mathrm{L}$ shaped plate is less stressed and less displaced than single straight plate ; and this may be due to the three dimensional design which leads to more stability than linear plate, as the single plate positioned more inferior the fracture gap decreased gradually, but the plate become highly stressed and deformed, and this can be managed by increasing the thickness of the plate or addition of another plate at the superior border these finding is in accordance to the study of Arbag et al. ${ }^{[17]}$

Through this study, L shaped plate that is located at the middle show little displacement than that is located at the inferior border or the superior border.

As regards the double straight plates system, it showed less stress and displacement than the single straight and L shaped plate, this may be due to the superior border plate absorbs more applied load and resist deformity so that the load reached the lower border plate is minimized so that the lower border late in double straight system showed less stress and displacement than single straight and L shaped plate and this is in accordance to the study of Wang et al. ${ }^{[7]}$ and the study of Arbag et al. ${ }^{[17]}$

While double L shaped plate showed less stress and displacement than double straight plate system and this may be due to the additional support provided by double L shaped plate that form rectangular construct surrounding the fracture line and more stability at three dimensions.

As regards torque moment, this research provides obvious torque loading where there is type of loading called moment load provided by FUSION software, and this clear torque loading is not provided through many researches that studied the mandibular behavior on treatment of the symphyseal fracture ${ }^{[18,19]}$.

As regards torque moment, the single $\mathrm{L}$ shaped plate show less stress and torque displacement than single straight plate, the torque stress on both single systems showed higher value at the lower border than the superior border, the least displacement value was recorded when the L shaped single plate placed at the middle as regards the double straight plate system it showed less stress and displacement than single plate systems either straight or L shaped plate. Also, the double L shaped plate showed less torque displacement and stress than double straight system.

In our study, high convergence was used for the results as regards the von Mises stresses and total displacement to obtain accurate solution and this is done by using finer elements in sequential steps till the solutions become stable and this done according to the study of Ayali et al. ${ }^{[18]}$

Through this study, acrylic material was used for mechanical testing because it is similar to mandibular bone, and used for this purpose in literature ${ }^{[20,21]}$.

\section{CONCLUSION AND RECOMMENDATION}

From the mentioned discussion, the following can be concluded:

1- Double plates can provide more stability for healing of the fracture.

2- L shaped plate design gives more stability than straight plate of the length and dimension.

3- Changing the position of the single plate affect the stability of the fracture, middle positioning of the single plate may give more stability than other positions.

4- Finite element methods is valuable conservative technology can be used for designing of the fixation systems and selection the optimum positioning for their application.

\section{CONFLICT OF INTEREST}

There are no conflicts of interests.

\section{REFERENCES}

1. Subhashraj K, Nandakumar N, Ravindran C. Review of maxillofacial injuries in Chennai, India: a study of 2748 cases. Br J Oral Maxillofac Surg. 22:298-302.2007

2. Tams J, Otten B, van Loon JP, et al. A computer study of fracture mobility and strain on biodegradable plates used for fixation of mandibular fractures. J Oral Maxillofac Surg; 57:973, 1999

3. Mathog RH, Toma V, Clayman L, Wolf S. Nonunion of the, mandible: an analysis of contributing factors. J Oral Maxillofac Surg 58: 746-752.2000

4. Joshi U and Manju Kurakar M. Comparison of Stability of Fracture Segments in Mandible Fracture Treated with Different Designs of MiniPlates Using FEM Analysis J Oral Maxillofac Surg 13(3):310-319.2014

5. Ji B,Wang C, Liu L. A biomechanical analysis of titanium miniplates used for treatment of mandibular symphyseal fractures with the finite element method, J Oral Maxillofac Surg 109:21-27, 2010

6. Al-Khateeb S, Al Maaitah E, Abu Alhaijac E, Badrand S. Mandibular symphysis morphology and dimensions 
in different anteroposterior jaw relationships, Angle Orthod. 284:304-309.2014

7. Wang H. Baohui Ji, Jiang, W, liu L, Zhang, Tang W, and Tian and Fan. Y, Three, Dimensional Finite Element Analysis of Mechanical Stress in Symphyseal fractured Human Mandible Reduced With Miniplates During Mastication J Oral Maxillofac Surg. Jul;68(7):1585-92. 2010

8. Ayali A and Erkmen E. Biomechanical Evaluation of Different Plating Methods Used in Mandibular Angle Fractures with 3-Dimensional Finite Element Analysis: Favorable Fractures J Oral Maxillofac Surg 75:1464-1474, 2017

9. Dogru S, Cansize E and Arslan Y. A review of finite element applications in oral and maxillofacial biomechanics. Journal of mechanics in medicine and biology 18(2) .2-26.2018

10. Erkmen E, Şimşek B, Yücel E, Kurt A. Threedimensional finite element analysis used to compare methods of fixation after sagittal split ramus osteotomy: setback surgery posterior loading. Br J Oral Maxillofac Surg; 43(2):97104. 2005

11. Cox T, Kohn MW, Impelluso T. Computerized analysis of resorbable polymer plates and screws for the rigid fixation of mandibular angle fractures. J Oral Maxillofac Surg 61:481, 2003

12. Wagner A, Krach W, Schicho K, et al. A 3-dimensional finite element analysis investigating the biomechanical behavior of the mandible and plate osteosynthesis in cases of fractures of the condylar process. Oral Surg Oral Med Oral Pathol Oral 94(6):678-86. 2002

13. Burn JS, Hansen JE. The use of microplates for internal fixation of mandibular fractures. Plast Reconst Surg. 125(5):1485-1492.2010

14. Hsu ML, Chen FC, Kao HC, Cheng CK. Influence of axis loading of an anterior maxillary implant:
A 3-dimensional finite element analysis, Int $\mathrm{J}$ Oral Maxillofac Implants 22:301-309, 2007

15. Kshirsagar R.Jaggi $\mathrm{N}$ and Halli R. bite Force Measurement in Mandibular Parasymphyseal Fractures: A Preliminary Clinical Study. Craniomaxillofacial trauma and reconstruction 4(4):241, 2011

16. Haug.R, Street.C and Goltz.M. Does plate adaptation affect stability .q biomechanical comparison of locking and nonlocking plates. J Oral Maxillofacial. 60, 1319. 2002

17. Arbag,H M, Korkmaz, H. Ozturk $\mathrm{K}$ and Uyar, Y - Comparative evaluation of different miniplates for internal fixation of mandible fracture using finite element analysis. J Oral Maxillofac Surg, 66,1225-12321. 2008

18. Ahmed S, S Bhardwaj, Ansari M , Farooqd O, and Khane A. Role of $1.5 \mathrm{~mm}$ microplates in treatment of symphyseal fracture of mandible: A stress analysis based comparative study Journal of Oral Biology and Craniofacial Research 7 .119-122.2017.

19. Kimura K, Nagasao T,1 Kaneko T, Miyamoto $\mathrm{J}$ and Nakajima T. A comparative study of most suitable miniplate fixation for mandibular symphysis fracture using a finite element model KeioJ Med 55(1):1-8,2005

20. Vieriu R, Țănculescu O, Mocanu, F Aniculăesă A, Doloca A, Luchian Mârțu S, Popa G. The validation of an acrylic resin for the completion of biomechanical studies on a mandibular mode. Romanian journal of oral rehabilitation 7:2.2015

21. Feller K, Richter G, Schneider M, Eckelt U. Combination of microplate and miniplate for osteosynthesis of mandibular fractures: an experimental study. Int. $\mathrm{J}$ Oral Maxillofac. Surg. 31:78.2002 